\title{
OIL ENTRAPPED FLOATING MULTIPARTICULATE SYSTEM OF CIPROFLOXACIN USING SODIUM ALGINATE BY EMULSION GELATION TECHNIQUE
}

\author{
*Shashank Soni ${ }^{1}$, Mustafa Ahmad ${ }^{1}$, Shikha Deshwal ${ }^{2}$ \\ ${ }^{1}$ Department of Pharmaceutics, Smt. Tarawati Institute of Bio medical and allied sciences, Roorkee, India \\ ${ }^{2}$ Department of Pharmaceutics, IFTM University, Moradabad, India \\ *Correspondence author's E-mail: shashank_soni64@yahoo.com Contact no: +919410572306
}

Received 16 July 2012; Review Completed 10 Aug 2012; Accepted 26 Aug 2012, Available online 15 Sep 2012

\begin{abstract}
The objective of this present work is to develop gastroretentive multiunit emulsion beads based on the oil for the sustaining effect of the Ciprofloxacin (CPX). By the technique which is based on emulsion gelation technique different oil was taken and incorporated in the mixture of CPX and sodium alginate (SA) as a hydrophilic polymer and this is extruded with the help of syringe in $4 \%$ calcium chloride cross linking solution having curing time of $10 \mathrm{~min}$. Prepared emulsion beads show a better portfolio in terms of drug release. The conventional emulsion beads (F4) shows a burst effect due to no incorporation of oil in it. Use of oil in the formulation acts as a barrier with SA and prolongs the effect of drug in the upper GI tract for a longer period of time and may be used in the treatment of upper GI tract infection. Other formulations in which oil used (F1, F2. F3) proves a better sustaining effect as compared to formulation (F4) and it was found that sodium alginate not only effective for the sustaining effect of drug alone. With use of oil and sodium alginates it proves a better polymer for this drug. Data obtained from our present investigation we find out that retardation of the drug from the matrixes of drug in following order mentha oil > light liquid paraffin > castor oil and also explains the better encapsulation efficiency, \% buoyancy and release profile.

Key words: Ciprofloxacin, Sodium alginate, emulsion gelation technique, curing time, \% buoyancy
\end{abstract}

\section{INTRODUCTION}

As a naturally occurring biopolymer, alginate has been used successfully in the pharmaceutical industry as a gelling agent and colloidal stabilizer, and holds strong potential in the area of drug delivery. Extracted from brown algae, alginate polymers consist of linear, unbranched polysaccharides with acid residues of 1, 4'linked- $\beta$-D-mannuronic acid and $\alpha$-L-gluronic acid residues. The residues are arranged in blocks along the chain and vary in sequence and composition. There are numerous physical characteristics possessed by alginate that enable it to form matrices to encapsulate and deliver various proteins and cells in vivo. Specifically, alginate matrices contain aqueous internal environments ideal for the encapsulation of proteins and small molecules. These encapsulations form at room temperature, independent of organic solvents, and they have a high rate of macromolecular diffusion due to their porous gel state that may be controlled through specific coating procedures. In addition, alginate matrices are very biodegradable and can be broken down under normal physiological conditions ${ }^{1}$.

The preparation of alginate beads containing an assortment of substances can be achieved through various means. These approaches cover large bead preparation, microbead preparation, matrix block preparation, and in situ gelling systems. In general, alginate beads are formed when a solution of sodium alginate and the desired substance is extruded as droplets into a divalent solution to encourage cross-linking of the polymers. Such cross-linking solutions may include cations such as $\mathrm{Ca}^{2+}, \mathrm{Sr}^{2+}$ or $\mathrm{Ba}^{2+}$, while monovalent cations and $\mathrm{Mg}^{2+}$ do not induce gelation, and $\mathrm{Ba}^{2+}$ and $\mathrm{Sr}^{2+}$ ions produce very strong alginate gels (Clark and Ross-Murphy., 1987). Numerous other cations including $\mathrm{Pb}^{2+}, \mathrm{Cu}^{2+}, \mathrm{Cd}^{2+}, \mathrm{Co}^{2+}, \mathrm{Ni}^{2+}, \mathrm{Zn}^{2+}$, and $\mathrm{Mn}^{2+}$ will induce gelation, but due to their toxicity they are rarely used. In the gelation process, the polymer chains are crosslinked by the exchange of sodium ions from gluronic acids with divalent cations, forming what is referred to as the "egg-box" 2 as represented in Figure 1.

In the present investigation, an extended and controlled release composition and formulation of Ciprofloxacin, which is a synthetic antimicrobial having a quinolone structure and broad spectrum antibiotic capable of providing detectable blood levels over $10 \mathrm{hr}$ was formulated using expandable, gelling, swellable hydrocolloid polymer along with the variety of oils which acts as a barrier in retardation of drug from these beads matrixes using calcium chloride as a cross linking agent. Although many drugs have been extensively investigated using natural polymeric carrier, the studies on the release of antibiotic drugs are limited.

The use of oil entrapped calcium pectinate beads has been used in various ways for sustained release of drugs or for the targeting drugs to colon $^{3}$. Theophylline tablets composed of mineral oil entrapped agar for the controlled release $^{4}$ have been reported. Sodium alginate emulsion beads for extended release formulations have not been tested. The effects of factor like type of oil, percentage of oil on the prepared beads were investigated. 

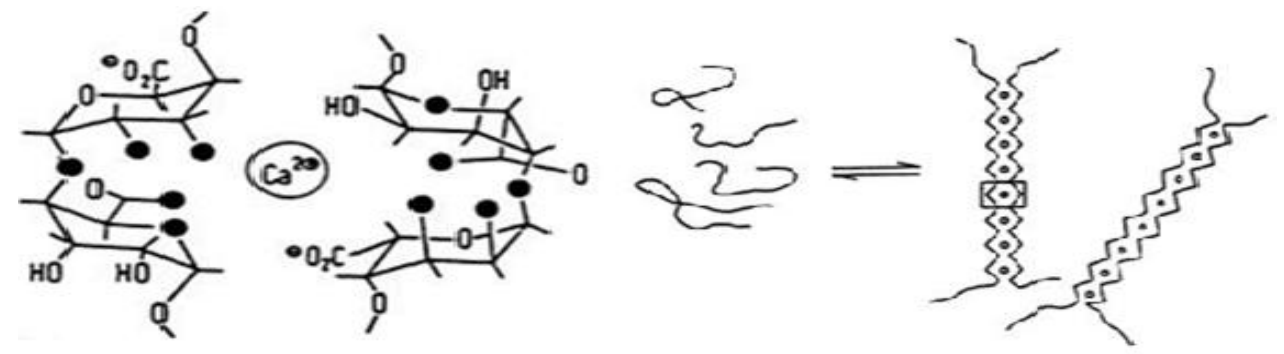

Figure 1: Egg box association of poly L- guluronate sequences of alginate and conversion of random coils to ribbon structures when cross linked with $\mathrm{ca}^{2+}$ ions.

\section{MATERIALS AND METHODS}

\section{Materials}

Ciprofloxacin (CPX) was gifted by Axa parenteral, India. Sodium alginate was purchased from Sigma-Aldrich (St. Louis, USA). Water used in the formulations was of HPLC grade (Merck) and all other chemicals used were of analytical grade.

Methods
Floating beads were prepared by (Table 1) by extruding an SA containing different grades of oil with drug with the help of $25 \mathrm{ml}$ hypodermic syringe, into $\mathrm{CaCl}_{2}$ solution $(4 \% \mathrm{w} / \mathrm{v})$ at room temperature $\left(28^{\circ} \mathrm{C}\right)$. The beads formed instantaneously, were cured for 10 minutes in gelation medium at $37{ }^{\circ} \mathrm{C}$ with mild agitation. Prepared beads were separated by filtration, washed thrice with deionized water and dried in an oven at $35{ }^{\circ} \mathrm{C}$ for 12 hours than kept in a desiccator for another 12 hours before further experiments.

Table 1: Formulation composition of alginate beads

\begin{tabular}{lllccccc}
\hline $\begin{array}{c}\text { Formulation } \\
\text { code }\end{array}$ & $\begin{array}{c}\text { CPX } \\
(\mathbf{m g})\end{array}$ & $\begin{array}{c}\text { S.A } \\
(\boldsymbol{\%} \mathbf{w} / \mathbf{v})\end{array}$ & $\begin{array}{c}\text { Mentha oil } \\
(\mathbf{m l})\end{array}$ & $\begin{array}{c}\text { Light liquid paraffin } \\
(\mathbf{m l})\end{array}$ & $\begin{array}{c}\text { Castor oil } \\
(\mathbf{m l})\end{array}$ & $\begin{array}{c}\text { Calcium Curing } \\
\text { chloride }\end{array}$ & $\begin{array}{c}\text { time } \\
\text { time }\end{array}$ \\
\hline F1 & 100 & 1.5 & 1.5 & & & $4 \%$ & $10 \mathrm{~min}$. \\
F2 & 100 & 1.5 & & 1.5 & 1.5 & $4 \%$ & $10 \mathrm{~min}$. \\
F3 & 100 & 1.5 & & & & $4 \% \mathrm{~min}$. & $10 \mathrm{~min}$. \\
F4 & 100 & 1.5 & & & & $4 \%$ \\
\hline
\end{tabular}

\section{RESULTS}

\section{Particle size characterization}

Particle size was made by using optical microscope by calibrating it with eye piece and stage piece micrometer (Model BH-2, Olympus, Japan). The readings were made in triplicate and standard deviation was calculated. The particle size varies from $1.06 \pm 0.14$ to $1.24 \pm 0.13 \mathrm{~mm}$. The main reason for this fluctuation in the particle size range is due to the nature of oil used.

F3 formulation is having the largest particle size due to the nature of oil used and its concentration. Castor oil used shows some tackiness in its character and it has more density and volatility when compared with the other formulations oil used. This density and volatility also plays an important role in the size and sphericity of the formulation [5]. An incorporation of increase in concentration and volume of oil leads to the increase in size as well as change in sphericity of the emulsion beads.

Volatility of the oil used also plays a vital role in the formulation. As the density of oil decreased the volatility increased. When these beads are dried the higher volatile oil evaporated quickly leading to the uneven morphological characteristics. Formulation (F4) having the smallest size due to the composition only of CPX and SA. It has the particle size of $1.06 \pm 0.14$.
Total volume of formulation was $10 \mathrm{ml}$

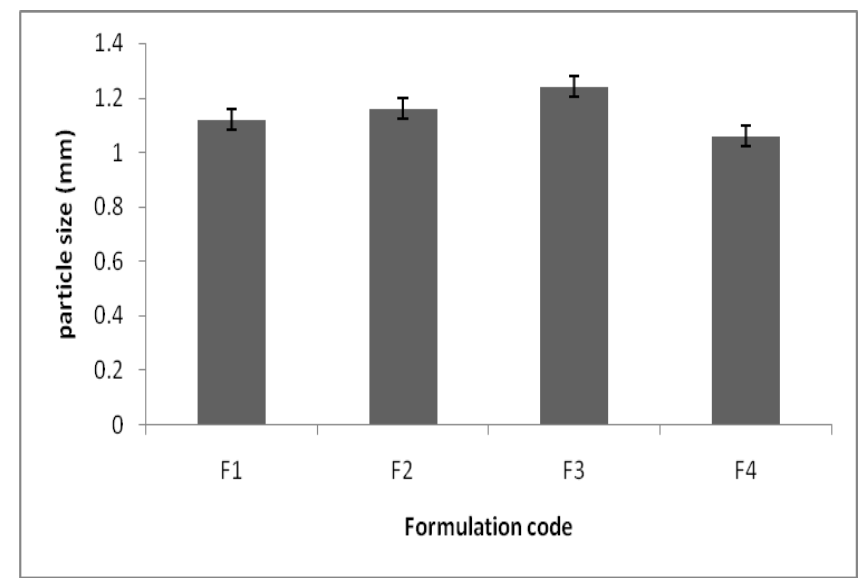

Figure 2: Histogram representing particle size (mm)

Formulation (F1) having the particle size of $1.12 \pm 0.09$ due to of volatility nature of menthe oil used because when these beads are dried the volatile oil component evaporated quickly leading to the uneven morphological profile and also alters the decreased in the particle size.

Formulation (F2) shows the particle size of $1.16 \pm 0.10$ also attributes the same phenomenon of nature of light liquid paraffin which has somewhat increase in viscosity which alters the morphology and size of the beads as compared to formulation (F3). 


\section{Drug entrapment efficiency}

The drug entrapment efficiency of each formulation was determined by extracting the crushed beads with $0.1 \mathrm{M} \mathrm{HCl}$ (pH 1.2) for $180 \mathrm{~min}$ at $37{ }^{\circ} \mathrm{C}$ and then centrifuged at 5000 rpm (Remi centrifuge). The supernatant layer was taken and suitably diluted with $0.1 \mathrm{M} \mathrm{HCl}(\mathrm{pH} 1.2)$ buffer, quantifying the amount of drug UV spectrophotometrically at $277 \mathrm{~nm}$. The entrapment efficiency (EE) was calculated according to relationship:

$$
E E=\frac{\text { Actual drug content }}{\text { Theorectical drug cont ent }} \times 100
$$

Formulation F1, F2, F3, F4 having the \% entrapment efficiency of $77.12 \pm 0.12,82.09 \pm 0.21,84.34 \pm 0.31$, $71.13 \pm 0.26$ respectively. Curing time is the most important factor for such types of results. Most of the drug diffuses out from the SA matrixes to the surrounding aqueous medium resulting in this entrapment efficiency. To overcome from this the curing time may be increased which may overcome this problem. The second and very most important consideration for this problem is the leakage of oil from the formulation. F1 formulation shows the $\%$ entrapment efficiency of $77.12 \pm 0.12$ which is only due to the leakage of oil from the as seen during the preparation phase and not act as a barrier for release of the drug CPX.

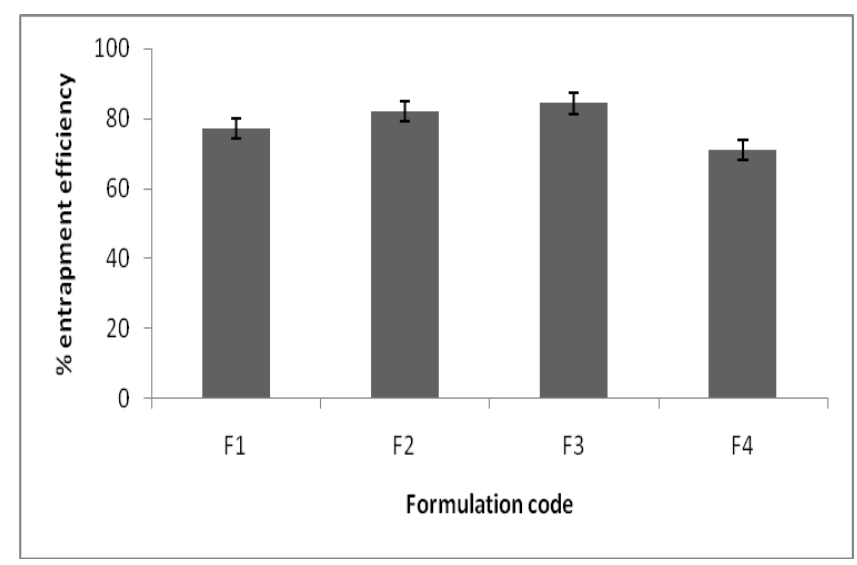

Figure 3: Histogram representing\% entrapment efficiency

\section{Assessment of in vitro buoyancy of the floating beads}

The buoyancy of the gel beads was not dependent upon the hydrophilic polymer i.e sodium alginate concentration. Beads prepared with gas-generating agent remained buoyant on $0.1 \mathrm{M} \mathrm{HCl}$ for sufficiently long duration of time. Floating beads remained buoyant for upto 12 hours on $0.1 \mathrm{M} \mathrm{HCl}$ with no floating lag time. Upon contact with an acidic medium, the $\mathrm{CaCO}_{3}$ effervesced, releasing $\mathrm{CO}_{2}$. The released $\mathrm{CO}_{2}$ was entrapped in the gel network of sodium alginate producing buoyant formulation and thus, prolonged floating of beads.

However data obtained for \% buoyancy as depicted in table reveals that the due to the incorporation of the oil in the formulation leads to increase in buoyancy factor as clearly seen in the F1 and F2 formulation, in F3 formulation the buoyancy factor somewhat decrease due to the nature of oil which has somewhat related to the density factor and the conventional F4 formulation leads to the 89 $\%$ of buoyancy factor.

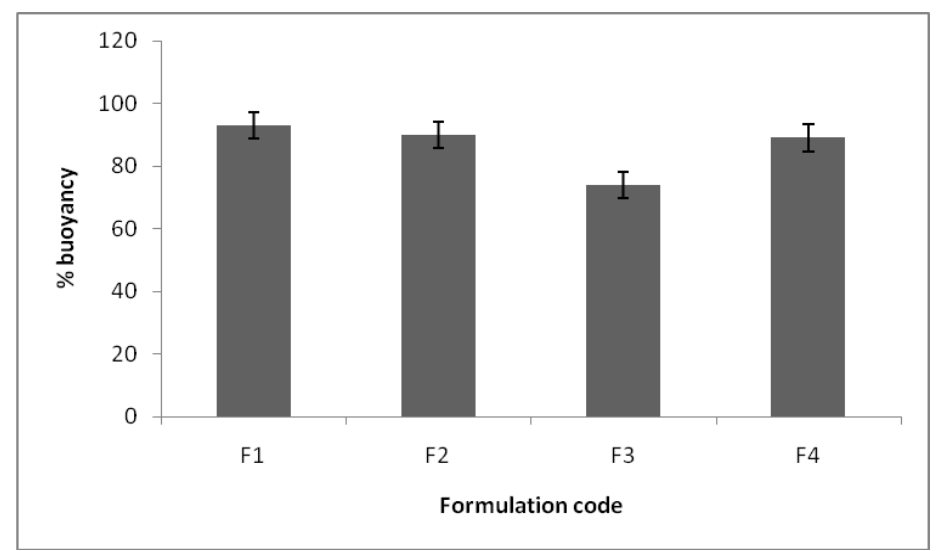

Figure 4: Histogram representing\% buoyancy

\section{Determination of density}

In human stomach fluid is having a density of $1.004 \mathrm{~g} / \mathrm{cm}^{3}$. The object remains afloat in the stomach whose specific density is less than $1.004 \mathrm{~g} / \mathrm{cm}^{3}$. So the density of the beads system is determined by using formula Density (d) was determined using the relationship $\mathrm{d}=\mathrm{m} / \mathrm{v}$ where $\mathrm{v}=$ $\pi r^{2} h$. Density ranges from $0.94-0.98 \mathrm{~g} / \mathrm{cm}^{3}$.

Table 2: Representing particle size, \% entrapment efficiency, \% buoyancy, lag time and density of the formulations

\begin{tabular}{rrrrrrr}
\hline $\begin{array}{c}\text { Formulation } \\
\text { Code }\end{array}$ & $\begin{array}{c}\text { Particle size } \pm \\
\text { S.D }(\mathbf{m m})\end{array}$ & $\begin{array}{c}\text { \% E.E } \pm \\
\text { S.D }(\mathbf{m m})\end{array}$ & $\begin{array}{c}\text { \% } \\
\text { buoyancy }\end{array}$ & $\begin{array}{c}\text { Lag } \\
\text { time }\end{array}$ & $\begin{array}{c}\text { Density } \\
\left(\mathbf{g} / \mathbf{c m}^{\mathbf{3}}\right)\end{array}$ \\
\hline F1 & $1.12 \pm 0.08$ & $77.12 \pm 0.12$ & 93 & 3 min & 0.94 \\
& F2 & $1.16 \pm 0.10$ & $82.09 \pm 0.21$ & 90 & 5 min & 0.93 \\
F3 & $1.24 \pm 0.13$ & $84.34 \pm 0.31$ & 74 & 90 min & 0.94 \\
F4 & $1.06 \pm 0.14$ & $71.13 \pm 0.26$ & 89 & 15 min & 0.98 \\
\hline
\end{tabular}




\section{In vitro release profile}

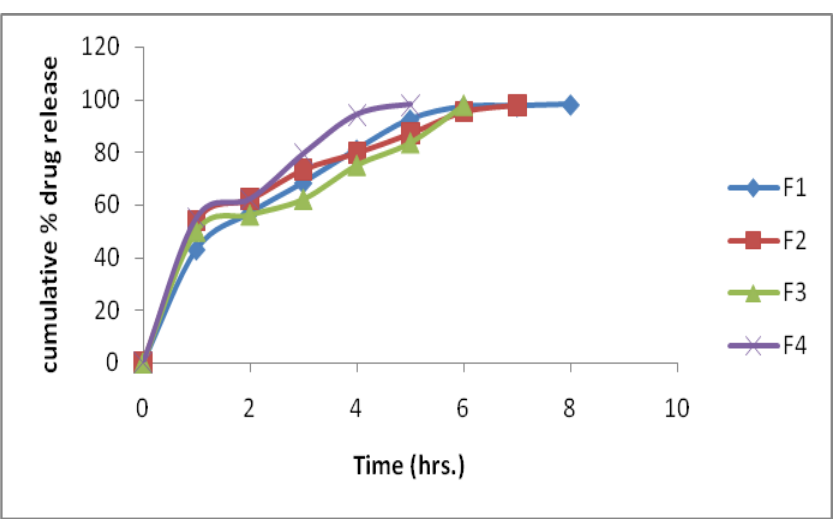

Figure 5: Release profile of formulations in $0.1 \mathrm{M} \mathrm{HCl}$ (pH 1.2)

In vitro release profile was performed in dissolution apparatus type II (paddle type, Electrolab, Mumbai, India) in $0.1 \mathrm{M} \mathrm{HCl}(\mathrm{pH} 1.2)$ at $50 \mathrm{rpm}$.

Carried dissolution study however indicates that the there is rapid release of the drug in the initial phase however after that there is steady drug release takes place for a prolonged period of time. This is due to the drug is dragged to the outer surface of the beads during preparation process that gives the burst effect. Formulation F4 shows the burst effect because it has only the composition of drug and polymer and this single layer of polymer is not effective in barrier of drug release as shown in the above formulations. Formulation F1, F2, F3 have oil composition and this act as a barrier for drug release along with Sodium alginate and sustained the release of a drug from 8 hours to 10 hours.

The release profile reveals that the sustaining effect was more effective in Formulation F1, F2, F3 in order of mentha oil > light liquid paraffin > castor oil whereas formulation F4 which is conventional formulation shows the burst effect release.

\section{Release kinetics of formulation}

In order to describe the kinetics of drug release from formulations, various equations were used, such as the zero-order rate equation, which describes the systems where the release rate is independent of the concentration of the dissolved species 6. The first-order equation describes the release from systems where dissolution rate is dependent on the concentration of the dissolving species.

In vitro data were also fitted to Higuchi's square root model ${ }^{7}$, which describes the release from systems where the solid drug is dispersed in an insoluble matrix, and the rate of drug release is related to the rate of drug diffusion. Under some experimental situations the release mechanism deviates from the Fick's equation, following an anomalous behaviour (non-Fickian release). In these cases a more generic equation can be used. Korsmeyer et al. developed a simple, semi-empirical model, relating exponentially the drug release to the elapsed time (Eq. [1]).

$$
M t / M \infty=K t^{n}
$$

where $M t / M \infty$ is the fraction of drug released at time $t ; K$ is a constant comprising the structural and geometric characteristics of beads; and $n$, the release exponent, is a parameter that depends on the release

In case of CPX loaded oil emulsion beads, formulation F1, F3 and F2 followed zero order kinetics as evidenced by $\mathrm{r}^{2}$ values, which were higher when fitted to zero order kinetics which explains that the drug release rate is independent of its concentration. Whereas, formulation F4, followed Higuchi kinetics, as evidenced by $r^{2}$ values. The $\mathrm{n}$ values from drug release experiment ranged from 0.44 0.48 , with formulations F1 and F4 followed Quasi-Fickian diffusion and formulations F2, F3 followed anomalous non-Fickian diffusion.

Table 3: Release kinetics of CPX from oil fabricated beads

\begin{tabular}{|l|l|l|l|l|l|}
\hline \multirow{2}{*}{ Formulation Code } & \multicolumn{4}{|c|}{$\mathbf{r}^{2}$ Value } & \multirow{2}{*}{ n value } \\
\cline { 2 - 5 } & \multicolumn{1}{|c|}{ Zero order } & First order & Higuchi & \multicolumn{1}{c|}{$\begin{array}{c}\text { Korsmeyer- } \\
\text { Peppa's }\end{array}$} & \\
\hline F1 & 0.9739 & 0.5321 & 0.9709 & 0.9829 & 0.44 \\
\hline F2 & 0.9641 & 0.5289 & 0.9894 & 0.9906 & 0.52 \\
\hline F3 & 0.9846 & 0.5735 & 0.9741 & 0.9914 & 0.55 \\
\hline F4 & 0.9525 & 0.5195 & 0.9926 & 0.9976 & 0.48 \\
\hline
\end{tabular}

\section{DISCUSSION AND CONCLUSION}

The main objective of present investigation was to prepare sodium alginate-oil based complex beads in one step with the use of crosslinking agent and to explore the potential of the prepared beads in the oral delivery of water soluble drug. The different grades of oil used define the status of generally regarded as safe status (GRAS). Use of oil during our present investigation acts as a barrier and sustained the drug for a prolonged period of time. Our present investigation result shows that it is possible to (C) 2011, JDDT. All Rights Reserved develop a system which is based on oil by emulsion gelation technique and proves a better in terms of sustaining effect of the drug. The prepared beads examined for encapsulation efficiency, buoyancy behaviour and drug release profile study. These beads show better results in terms of release profile and extend the release of a drug for 10-12 hours. These systems however may be beneficial in the treatment of stomach specific infections; however it needs more study. 


\section{ACKNOWLEDGEMENT}

Authors are thankful to Dr. Pankaj Sharma, Director of Smt. Tarawati institute of Bio medical and allied sciences, Roorkee, India for providing institutional funds to carry

\section{REFERENCES}

1. Mahkam M, Bioadhesive alginate copolymers as platforms for oral delivery of insulin, Nature and science, 2009, 7(6), 61-69

2. Chan LW, JinY, Heng PWS, Cross linking mechanisms of calcium and zinc in the production of alginate microspheres, International Journal of Pharmaceutics 2002, 242, 255-258

3. Sriamornsak $\mathrm{P}$, Thirawong $\mathrm{N}$, Puttipipatkhachorn $\mathrm{S}$, Morphology and buoyancy of oil entrapped calcium pectinate gel beads, The AAPS Journal, 2004, 6, 23-28

4. Desai S, Bolto S, Enhancement of drug bioavailability by floating drug delivery system, Pharm Research, 1993, 10, 1321-1325.

5. Rouge N, Buri P, Doelker E, Gastroretentive dosages as a potential tool for enhancing the efficacy of antibiotics: A review, Int. J. Pharm., 1996, 136, 117-139

6. Bourne, DWA. Pharmacokinetics. In: Modern Pharmaceutics (GS Banker \& CT Rhodes, ed.) 4th ed., Marcel Dekker Inc., New York, 67-92

7. Higuchi T, Mechanism of sustained-action medication theoretical analysis of rate of release of solid drug dispersed in solid matrices, J. Pharm. Sci. 1963, 52, 1145-9. out the research work. Authors are also thankful to Axa parentrals, India for providing a gift sample of ciprofloxacin and Sigma Aldrich for providing the Sodium alginate in time. 